\title{
Discursos de professores de Ciências sobre suas práticas educativas: as aulas de Química nos anos finais do Ensino Fundamental
}

Amanda Pini Semensate amandasemensate@hotmail,com Universidade Estadual de Maringá

Débora Piai Cedran piaidebora31@gmail.com Universidade Estadual de Maringá (UEM), Maringá, Paraná, Brasil

\section{RESUMO}

O ensino de Ciências Naturais nos anos finais do Ensino Fundamental passou a ser obrigatório pela Lei $n^{\circ} 5.692 / 71$, e mais especificamente, no nono ano se estuda a Química e a Física, como é orientado pelos Parâmetros Curriculares Nacionais - PCNs. Assim, as práticas pedagógicas utilizadas pelos professores são de grande importância para que o ensino de ciências não seja uma dificuldade para os alunos alcançando os objetivos de ajudar a compreender o mundo e atuar como indivíduo e como cidadão, utilizando conhecimentos de natureza científica e tecnológica. Dessa forma, a presente pesquisa, teve como finalidade, investigar as práticas de professores de ciências nos anos finais do Ensino Fundamental. Os dados deste estudo, obtidos por meio de uma entrevista semiestruturada, realizada com cinco professores de três escolas da rede pública de ensino, das cidades de Maringá e Atalaia, revelam que os professores possuem dificuldades em desenvolver práticas educativas que atendam aos PCNs, relacionados à Química, como por exemplo, a contextualização dos conteúdos e o seu desenvolvimento por meio de temas, além da experimentação.

PALAVRAS-CHAVE: Ensino de Ciências. Formação Docente. Práticas Docentes. 


\section{INTRODUÇÃO}

A disciplina de Ciências no Ensino Fundamental deve proporcionar aos alunos uma formação cidadã, para atuarem em sociedade utilizando os conhecimentos científicos em suas escolhas, constituindo-se de extrema importância no processo de aprendizagem dos alunos. Dessa forma, o presente estudo visou investigar o discurso de professores do nono ano do Ensino Fundamental, que lecionam Ciências, quanto às suas práticas educativas, tendo em vista o conteúdo de Química segundo as orientações dos Parâmetros Curriculares Nacionais - PCNs. A escolha do nono ano se deu por ser uma série que abrange mais especificamente a Química no Ensino Fundamental, visto que, os alunos apresentam grande dificuldade nessa disciplina ao ingressarem no Ensino Médio. Logo, quando se conhecem as práticas educativas, que segundo autores como, Zabala (1998), Cabrero et al., (2008) e Delizoicov et al., (2002), são ações que restringem a procedimentos e teorias científicas, mas dependem de crenças e pressupostos teóricos dos professores, que interferem diretamente na aprendizagem dos alunos, é possível refletir sobre elas, não importando se são práticas problemáticas ou não, objetivando a melhoria na formação inicial e também continuada de professores. Para alcançar esse propósito, realizou-se entrevistas com cinco professores e analisaram-se as gravações dessas entrevistas, por meio da Análise Textual Discursiva.

\section{PRESSUPOSTOS TEÓRICOS}

O ensino de ciências naturais passou a ser obrigatório em todas as séries do primeiro grau pela Lei $n^{\circ} 5.692 / 71$, e mais a frente passou a ser o quarto ciclo, ou seja, a última etapa do Ensino Fundamental, mais especificamente o $9^{\circ}$ ano, que abrange em seu currículo principalmente as disciplinas de Física e Química, segundo as orientações dos Parâmetros Curriculares Nacionais - PCNs. A matéria de Ciências é de grande importância para se viabilizar aos estudantes uma formação para a sociedade, tendo como objetivos compreender o mundo e atuar como indivíduo e como cidadão, utilizando conhecimentos de natureza científica e tecnológica (BRASIL, 1998).

Nesse sentido, Cachapuz et al., (2005) discute a relevância do ensino de ciências, utilizando o termo "alfabetização científica", no qual a prioridade não recai somente no ensino de conceitos, princípios e leis que podem formar especialistas em Química ou Física, mas sim, em uma educação e alfabetização mais geral, que auxilie todos os futuros cidadãos na compreensão das relações entre ciência, tecnologia, meio ambiente e sociedade, tornando-os capazes de opinar, tomar decisões e reconhecer a ciência como parte da cultura atual.

Sasseron e Carvalho (2008) defendem que a inclusão da alfabetização científica não deve ser exclusiva para o Ensino Médio ou Ensino Superior, ela deve ser introduzida já nos anos iniciais do Ensino Fundamental, na disciplina de Ciências, permitindo que os estudantes participem ativamente do processo de construção do conhecimento científico desde muito novos, se familiarizando com a proposta de investigação e resolução de problemas.

Deste modo, para que o aluno seja capaz de atuar como um cidadão crítico e construir uma relação entre ser humano e natureza, a escola e o professor devem 
aproximar o aluno do seu cotidiano, desenvolvendo competências e habilidades, como observar, registrar, se comunicar, estabelecer relações, entre outros, evidenciando a importância da Química e das Ciências da Natureza, além de constituir subsídios conceituais para as disciplinas mais específicas, que serão abordadas no Ensino Médio (MILARÉ, PINHO ALVES, 2010).

Certamente, a aproximação do aluno com o seu cotidiano, a alfabetização científica, a formação para a sociedade e o desenvolvimento de saberes, habilidades e competências, precisam ser mediados (FURMAN, 2009), e dependem de estratégias específicas e das práticas educativas dos professores. Delizoicov, et al. (2002) compreende a prática educativa como um conjunto de saberes e práticas, que não se restringem a procedimentos, conceituações, modelos ou teorias científicas.

Isto vem ao encontro do que afirma Sacristán (1999, p. 73), o qual julga que "a prática educativa é o produto final a partir do qual os profissionais adquirem o conhecimento prático que eles poderão aperfeiçoar". Sob o mesmo ponto de vista, compreende-se que as práticas educativas não são cumprimentos de teorias ou receitas (CUNHA, CAMPOS, 2010), pois envolvem costumes, concepções pessoais, reflexões, pressupostos teóricos e também crenças, que influenciam diretamente nas aulas dos professores.

Assim concordamos com Cabrero e colaboradores (2008) haja vista que,

\begin{abstract}
a prática educativa se concebe como um conjunto de situações em sala de aula, que configuram o trabalho do professor e dos alunos, em função de determinados objetivos de formação, circunscritos ao conjunto de ações que incidem diretamente na aprendizagem dos alunos (CABRERO, et al, 2008, p. 4).
\end{abstract}

Nesta direção, Zanon e Freitas (2007), discutem que as práticas educativas dos professores devem estar vinculadas a mediação, orientação, motivação, observação e principalmente reflexão.

Admitindo então as práticas educativas como um sistema complexo, autores como Zabala (1998) argumentam que não é possível reconhecer todos os fatores que definem as práticas educativas por possuírem várias determinantes, como organização, possibilidades, tradições metodológicas, valores, ideias e hábitos pedagógicos, que são considerados complexos, temporais, fluídos e interferem nas ações educativas.

Dessa maneira, no sentido de nortear a educação do Ensino Fundamental e Médio em todo o País, os Parâmetros Curriculares Nacionais - PCNs, indicam instrumentos e procedimentos que podem auxiliar os professores em suas práticas educativas, como a elaboração de atividades, que incluem aspectos como, problematização, investigação, experimentação, contextualização por meio de temas, e também critérios e instrumentos de avaliação, importantes para a formação social e humana do estudante e que o aproximem do seu cotidiano nessa etapa escolar, permitindo a investigação, a comunicação, e o debate de ideias (BRASIL, 1998).

Considerando então os PCNs como um dos possíveis orientadores das práticas educativas, torna-se substancial a inclusão de alguns aspectos, como a abordagem dos conteúdos, a avaliação, a experimentação, entre outros, nos processos de ensino. Assim, os PCNs para o quarto ciclo do Ensino Fundamental de Ciências 
Naturais, apresentam os conteúdos priorizados por meio de temas, sendo uma das diferentes propostas de ensino que busca a inter-relação das disciplinas de ciências, como exemplificado:

Por meio de temas de trabalho, o processo de ensino e aprendizagem na área de Ciências Naturais pode ser desenvolvido dentro de contextos social e culturalmente relevantes, que potencializam a aprendizagem significativa. Os temas devem ser flexiveis o suficiente para abrigar a curiosidade e as dúvidas dos estudantes, proporcionando a sistematização dos diferentes conteúdos e seu desenvolvimento histórico, conforme as características e necessidades das classes de alunos, nos diferentes ciclos (BRASIL, 1998, p. 28).

Dentre esses temas, pode-se discutir processos de poluição, investigando sobre a emissão de substâncias, partículas e materiais poluidores no ambiente, possibilitando o controle sobre ele, assim como, extração e produção de energia, transformações de energias e materiais, industrialização, desmatamento, valorização da qualidade de vida e saúde nesses aspectos. Além disso, apresentamse também temas, no qual o aluno pode entender as relações entre o corpo humano e o meio ambiente, a energia dos alimentos, além de investigar sobre os ciclos da água na natureza, valorizando a preservação da mesma.

Nessa perspectiva, o ensino por temas segundo Costa e Pinheiro (2013), é uma proposta que pode possibilitar a formação crítica, interdisciplinar e contextualizada, direcionando o estabelecimento de relações entre a Química, Física e também a Biologia, no qual, o professor deve julgar os temas mais pertinentes à realidade dos alunos, já que os conteúdos devem ser relevantes do ponto de vista social, cultural e científico, propondo e conduzindo os conhecimentos por meio de temas mais gerais e amplos. Logo, as práticas educativas devem estar voltadas para o desenvolvimento de temas com essas características, de modo que se priorize a formação ampla dos estudantes.

Outro aspecto importante, que deve ser contemplado e refletido nas práticas educativas são as várias formas de avaliação, citadas pelos PCNs (BRASIL, 1998), em que se tem como exemplos as pesquisas individuais e coletivas em diferentes fontes de informações, debates para solução de problemas e trabalhos para elaboração de textos informativos.

Autores, como Silva e Moradillo (2002), discutem, além das formas de avaliar, a importância da avaliação formativa, que também utiliza instrumentos variados, de forma processual, como discussões coletivas, cooperação entre aluno e professor, e o papel do professor como um orientador, deste modo, a avaliação é diária, e não tem como objetivo principal a classificação.

Assim, a avaliação torna-se um instrumento que constantemente deve ser pensando e repensando nas práticas educativas, já que, além de indicar se os objetivos e capacidades foram desenvolvidos para a formação dos alunos no decorrer das aulas, ela também reflete as perspectivas de ensino do professor e da escola, como as estratégias usadas pelo professor, avaliação como instrumentos da reflexão docente, ou seja, suas concepções de ensino.

Além dos processos avaliativos e da proposta de ensino por temas, a experimentação é um relevante instrumento para o ensino de Química e deve ser considerado nas reflexões das práticas educativas dos professores, aspecto este que é contemplado como destaque nos PCNs. 
$\mathrm{Na}$ perspectiva atual de experimentação, a construção do conhecimento científico não se dá pelo simples fato de fazer, mas sim, quando são propostas reflexões em que a teoria e a prática se conectam intimamente por meio da problematização, guiando os alunos em suas observações e desenvolvendo habilidades. Logo, o papel do professor é definir o problema, mediar às discussões sobre as hipóteses apresentadas pelos estudantes, para que estes consigam estabelecer relações entre os resultados obtidos, não somente pensando se o experimento deu certo ou errado, ou seja, a comprovação prática de teorias, como na perspectiva tradicional de experimentação. Dessa forma o estudante pode comparar e refletir sobre os conceitos químicos envolvidos nos experimentos, o que auxilia aprender a observar e entender a relevância da investigação científica e do fazer científico e tecnológico nas modificações de visão do mundo (BRASIL, 1998).

Dessa forma, foi possível notar a importância das práticas educativas, utilizando-se diferentes formas de avaliar e diferentes instrumentos que facilitam a aprendizagem dos alunos, e orientam a reflexão sobre a eficácia da prática do próprio professor, garantindo os objetivos propostos para o ensino de ciências naturais, que é de formar para a sociedade e compreender as relações ser humano e natureza.

Apesar da proposição destes objetivos de ensino, alguns autores como Milaré e Pinho Alves (2010), Arroio (2006), Pitombo e Marcondes (1992), apontam algumas dificuldades relacionadas à aprendizagem das Ciências, como por exemplo, a não compreensão de conceitos considerados abstratos para essa última etapa escolar, antes do Ensino Médio, a falta de interesse por parte dos alunos, limitações na elaboração e compreensão de modelos científicos e o surgimento de concepções alternativas. Segundo os autores, essas dificuldades podem ser ocasionadas devido à forma pela qual o conteúdo é desenvolvido, ou seja, pelo modo em que as práticas educativas são apresentadas, como o distanciamento dos conteúdos com as situações do dia a dia dos jovens, ensinando somente teorias e cálculos a serem memorizados, e também pelo excesso de conteúdos.

\section{DELINEAMENTO DA PESQUISA}

A realização dessa pesquisa se deu no ano de 2016, na disciplina de Pesquisa em Ensino de Química, do quarto ano no curso de Química Licenciatura, que tem como objetivo articular as diversas áreas da Química e outras áreas do conhecimento, identificar fontes de informações importantes para a formação do futuro docente e compreender a importância da pesquisa no ensino.

Para que os objetivos deste estudo, de investigar o discurso sobre as práticas educativas utilizadas por professores de Ciências em suas aulas de Química, fossem alcançados, a coleta de dados foi realizada por meio de uma entrevista semiestruturada, que segundo Minayo et al (2009), apresenta-se com questões abertas e fechadas, que permitem que o entrevistado converse sobre o tema, sem se prender às questões feitas. Sendo assim, a entrevista foi realizada com 05 professores de Ciências do nono ano do Ensino Fundamental que atuam em escolas da rede pública estadual de Maringá e Atalaia, no Estado do Paraná, e que 
apresentam formação em Ciências Biológicas, Ciências com Licenciatura Plena e Química Licenciatura.

A escolha do nono ano foi feita, pois é nessa série que se inicia mais amplamente os estudos de Química na disciplina de Ciências, logo, julgamos de extrema relevância conhecer o discurso sobre as práticas educativas utilizadas por professores de Ciências para o ensino de Ciências e da Química, pois quando se conhecem essas práticas, sendo elas boas ou problemáticas, se tem um ponto de partida para que sejam melhoradas, por meio das reflexões que podem ser feitas na Universidade, tanto na formação inicial de professores, quanto nas formações continuadas. Assim, para a realização da pesquisa, fez-se o contato com diversos professores da rede pública estadual, por telefone e pessoalmente, e dos diversos professores que foram contatados, cinco se dispuseram a participar da pesquisa.

Deste modo, a elaboração da entrevista semiestruturada se deu pela análise dos temas e conteúdos importantes para o ensino de Ciências, enfatizando a Química e as práticas educativas dos professores, com base nos temas, instrumentos e procedimentos apresentados pelos Parâmetros Curriculares Nacionais para o Ensino de Ciências (BRASIL, 1998), que forneceram subsídios e referenciais para a discussão do problema inicial nos resultados.

Assim, para se compreender melhor sobre as práticas educativas desses professores, foi questionado sobre a sua formação acadêmica, a utilização do laboratório, o uso do livro didático em aula, os conteúdos e temas que eles abordam em suas aulas, relacionado à Química, como a estrutura do átomo, tabela periódica, transformações químicas e físicas, energia dos alimentos, agentes poluidores, entre outros, e quais eles julgavam ser importantes ou não para essa etapa escolar, como também, as dificuldades enfrentadas pelos alunos em Química, as dificuldades da formação inicial dos professores e as formas de avaliações utilizadas.

Os dados foram obtidos por meio de gravações de áudio realizadas nas entrevistas, anotações da pesquisadora, e da questão fechada, no qual o professor assinalava os conteúdos e temas abordados por ele em sala de aula.

A análise desses dados foi realizada com base nas recorrências apresentadas nos relatos dos professores e utilizou-se a Análise Textual Discursiva (MORAES; GALIAZZI, 2011), na qual, segundo os autores, a metodologia permite ao pesquisador, maior profundidade sobre os dados, construindo novos sentidos e significados.

Esse processo de análise é realizado em etapas e, a primeira se inicia pela desconstrução e a unitarização dos dados em estudo, na qual consiste em fragmentá-lo, ressaltando os trechos mais importantes referentes aos critérios escolhidos, levando em consideração os objetivos da pesquisa. Nesse caso buscouse com a unitarização, perceber o discurso dos professores de Ciências sobre suas práticas em sala de aula. Isso foi possível por meio da gravação dos áudios durante a entrevista, assim, quando alguma fala se remetia à prática educativa, essa era destacada, resultando nas unidades de significado.

Para codificar essas unidades destacadas, atribuiu-se letras e números, que permitiram reconhecer a origem dos dados. Neste contexto, foi atribuída a letra $\mathrm{P}$ para distinguir cada professor, seguidos pela numeração de 1 à 5 , mantendo a discrição sobre a identidade de cada um. A segunda etapa foi a reescrita dessas 
unidades, atribuindo significado após a desconstrução do texto, mas mantendo a ideia inicial. Finalizando, a última etapa passou a ser a categorização, compreendida como o momento de atribuir títulos para as partes componentes dos textos, apresentando o contexto principal do mesmo ou foco do discurso, assim, com as unidades de significado destacadas, foi possível atribuir títulos às unidades que apresentavam uma regularidade, relacionando-as e buscando reunir o que é comum, por meio de uma interpretação da própria pesquisadora. Então, a categorização resultou nos seguintes focos de discurso: Experimentação, Conteúdos e Temas, Instrumentos avaliativos e Dificuldades na formação, expressos pelo Quadro 1.

\begin{tabular}{|c|c|}
\hline Unidades Indicadoras & Foco do discurso \\
\hline $\begin{array}{l}\text { "Levo eles no laboratório depois da teoria." } \\
\text { "[...]é depois da teoria." } \\
\text { "O laboratório do colégio é bom, tem materiais, } \\
\text { reagentes, vidrarias[...]" }\end{array}$ & Experimentação \\
\hline $\begin{array}{l}\text { "Nos materiais presentes no cotidiano dos alunos, eu } \\
\text { trabalhei [...] com rótulos, e com os átomos [...] ao } \\
\text { redor, relacionando eles com os nosso corpo, e com os } \\
\text { alimentos." } \\
\text { "Eu não tiraria nenhum conteúdo, porque o 9o ano é a } \\
\text { base pra ele chegar no Ensino Médio." }\end{array}$ & Conteúdos e Temas \\
\hline $\begin{array}{c}\text { "Exercícios para memorizar e depois prova, trabalhos, } \\
\text { relatório de aulas práticas[...]" } \\
\text { "Eu avalio com prova, quando ia pro laboratório eu } \\
\text { pedia relatório, anotações das observações, trabalho, } \\
\text { pesquisa em casa, ou nos livros em sala, tarefa, a feira } \\
\text { de ciências[...]" }\end{array}$ & Instrumentos avaliativos \\
\hline $\begin{array}{l}\text { "Nós não temos todo esse conhecimento de quem faz } \\
\text { só à Química, acho que deixa a desejar nas } \\
\text { licenciaturas." } \\
\text { "O que foi importante pra mim foi os cursos que a gente } \\
\text { fazia na universidade, de formação continuada anual." }\end{array}$ & Dificuldades na formação \\
\hline
\end{tabular}

Fonte: Autoria própria (2016).

\section{REFLEXÕES SOBRE A ANÁLISE DOS RESULTADOS}

Logo, na sequência das discussões, os focos de discurso que surgiram da categorização e foram apresentados no Quadro 1, serão abordados e argumentados com o auxílio de fundamentação e os pressupostos da investigação para a melhor compreensão dos resultados.

\section{EXPERIMENTAÇÃO}

Conforme indicado no Quadro 1, os relatos dos professores sobre suas práticas educativas, quando questionados sobre a utilização do laboratório em suas aulas e em que momento isso ocorria, indicam que os mesmos levam seus alunos ao laboratório ou realizam esse tipo de atividade, mesmo que de forma demonstrativa como relata P1 e P5. 
P1: "Eu já levei eles em laboratório nas soluções, na separação de componentes, nos ácidos, bases e sais, $\mathrm{pH}[\ldots]$ "..

P5: "Só faço demonstrativo[...] trabalhei com, identificação de substâncias, indicador ácido base, identificador de pH com papel tornassol."

No entanto, segundo o PCN, "[...]a experimentação, sem uma atitude investigativa mais ampla, não garante a aprendizagem dos conhecimentos científicos"(BRASIL, 1998, p. 20). Assim, apesar da preocupação dos professores com relação à experimentação, os elementos da investigação não são observados em suas práticas educativas, como se percebe nas falas destacadas abaixo, e acabam tratando essa atividade somente como comprovação de teoria, evidenciando a perspectiva tradicional de experimentação:

P1: "[...] experimento é depois da teoria."

P3: "Levo eles no laboratório depois da teoria."

P5: "Levo ao laboratório depois que eles já viram a teoria."

P4: "[...] então a gente dava teoria, trabalhava com exercícios, e já combinava com o técnico, tal dia vou dar aula prática."

Logo, a percepção dos professores sobre a função da experimentação como de comprovação de teorias ainda é frequente, como relatado por P1, P3, P4 e P5, que sempre levam seus alunos ao laboratório, mas, somente após ensinar os conceitos ou teorias.

Segundo alguns autores (NASCIMENTO, et al, 2010), essa prática educativa da experimentação, somente como observação para comprovação da teoria, se dá normalmente pela concepção de ciência do professor, no qual o cientista é neutro, isto é, observa sem hipóteses, realiza uma série de passos subsequentes para a simples comprovação. Nesse caso, os alunos assumem a mesma posição de observadores com o objetivo de interligar o experimento aos conceitos, o que nem sempre é trivial, pois os mesmos não conseguem estabelecer relações entre a teoria e a prática sem discussões ou reflexões que os impulsionem. Esse aspecto também é comentado por Giordan (1999):

\begin{abstract}
As idéias positivistas influenciaram e ainda influenciam práticas pedagógicas na área de ensino de ciências, sustentadas pela aplicação do método científico. Saber selecionar e hierarquizar variáveis segundo critérios de pertinência para a compreensão dos fenômenos, controlar e prever seus efeitos sobre os eventos experimentais, encadear logicamente sequências de dados extraídos de experimentos são consideradas, na visão positivista, competências de extremo valor para a educação científica do aluno (GIORDAN, 1999, p. 45).
\end{abstract}

Logo, essas competências, como assinalado por Giordan (1999), ainda são consideradas mais relevantes pelos professores, que possuem essa percepção de ciências, o que interfere em suas práticas educativas, pois o planejamento e os objetivos de ensino se voltarão para o desenvolvimento de tais competências.

No que diz respeito às condições para a realização da experimentação, quando questionado sobre a disposição de materiais e infraestrutura dos laboratórios, as escolas possuíam os materiais necessários para as práticas experimentais, como também estrutura de laboratórios adequados e suporte para a realização dos experimentos, como evidenciam P4 e P1: 
P4: "As práticas que eu fiz sempre teve material[...] e tem o laboratorista"

P1: "O laboratório do colégio é bom, tem materiais, reagentes, vidrarias[...]"

Assim, o suporte para executar essa prática é essencial, pois os professores de Química e Ciências, de modo geral, alegam dificuldades em desenvolver a experimentação, pela falta de estruturas das escolas (GONÇALVES; MARQUES, 2006). Logo, quando se possui condições, é possível potencializar a perspectiva atual de experimentação, que visa o processo de construção do conhecimento científico e tecnológico, que não se dá pelo simples fato de fazer, mas sim, quando há reflexões entre teoria e a prática, que normalmente são promovidas por meio das práticas educativas dos professores.

\section{CONTEÚDOS E TEMAS}

Com relação aos conteúdos e suas práticas educativas, dos 29 itens que foram ofertados, entre temas e conteúdos de Química, 23, em média, foram indicados por todos os 05 professores participantes da pesquisa. Dentre os temas, todos os professores assinalaram materiais presentes no ambiente e sua relação com a vida, transformações dos alimentos que ingerimos e três deles assinalaram energia dos alimentos. Já os temas, ciclos da água, agentes poluidores, produção dos materiais e seus efeitos, foram marcados por 01 ou 02 professores. Esses dados estão resumidos no Quadro 2:

Quadro 2 - Temas assinalados pelos professores.

\begin{tabular}{c|c|c|c|c|c}
\hline Temas & $\mathrm{P1}$ & $\mathrm{P2}$ & $\mathrm{P3}$ & $\mathrm{P4}$ & $\mathrm{P5}$ \\
\hline $\begin{array}{c}\text { Materiais presentes no ambiente e sua } \\
\text { relação com a vida }\end{array}$ & $\mathrm{X}$ & $\mathrm{X}$ & $\mathrm{X}$ & $\mathrm{X}$ & $\mathrm{X}$ \\
\hline $\begin{array}{c}\text { Transformações dos alimentos que ingerimos } \\
\text { Energia dos alimentos }\end{array}$ & $\mathrm{X}$ & $\mathrm{X}$ & $\mathrm{X}$ & $\mathrm{X}$ & $\mathrm{X}$ \\
\hline Ciclos da água & $\mathrm{X}$ & & & & $\mathrm{X}$ \\
\hline Agentes poluidores & & & $\mathrm{X}$ & & \\
\hline Produção de materiais e seus efeitos & & $\mathrm{X}$ & $\mathrm{X}$ & & \\
\hline
\end{tabular}

Fonte: Autoria própria (2016).

Assim, percebe-se que todos os professores escolheram, em suas práticas educativas, pelo menos um dos temas, para trabalhar e discutir os conteúdos, pensando na realidade do aluno e no ambiente escolar, isto é, evidenciado tanto pelas escolhas dos temas assinalados no quadro, quanto pela fala de P1:

P1: "Nos materiais presentes no cotidiano dos alunos, eu trabalhei com rótulos [...]e com os átomos [...] relacionando eles com os nosso corpo, e com os alimentos."

A relação dos conteúdos com o cotidiano, como destacado por $\mathrm{P} 1$, em que é trabalhada a análise da composição química dos rótulos de alimentos que os alunos ingerem em seu dia a dia, relacionando também aos átomos que estão presentes em cada parte do corpo humano, bem como os outros temas assinalados pelos professores, durante a entrevista, despertam o interesse e auxiliam na alfabetização científica dos alunos, já que se torna mais próximo o 
contexto dos conceitos quando relacionado ao seu cotidiano (BRASIL, 1998). O tratamento de temas também potencializa uma formação crítica e mais ampla por parte dos professores, oferecendo mais alternativas de intervenções didáticas na difícil função de planejar por meio de temas, conhecendo cada vez mais as possibilidades de se trabalhar nessa perspectiva.

Apesar da prerrogativa de que os professores entrevistados trabalham com alguns temas, pode-se questionar o entendimento que se tem por tal perspectiva, pois suas afirmações são genéricas e a escolha desses temas pode envolver seu emprego superficial. Assim, se por um lado os professores de Ciência indicam a questão dos temas presente em suas práticas, por outro lado, alguns conteúdos que também foram assinalados pelos professores, como balanceamento de equações, equações químicas, ligações químicas e estrutura do átomo, mostram a sobrecarga de conteúdos tratados no nono ano. A consideração que se faz é que estes conteúdos devem ser abordados pelos professores somente de forma qualitativa sem maiores detalhamentos sobre o nível microscópico, para que se compreenda a existência do átomo e dos seus rearranjos nas transformações químicas, como se afirma nos PCNs:

\footnotetext{
[...]as equações Químicas ainda devem ser abordadas de modo qualitativo, considerando-se quais os reagentes, as condições da reação e seus produtos, o que já é suficientemente difícil para este grau de escolaridade. No final deste ciclo é importante, contudo, que os estudantes tenham apreendido a idéia de que uma grande variedade de fenômenos pode ser explicada pela existência de variedades de arranjos entre pequenas partículas da matéria. A partir de vários exemplos, reconhecem também que duas ou mais diferentes substâncias combinam-se em produtos que têm propriedades distintas daqueles que lhe deram origem. Mas deve ser evitado pelo professor detalhar o que acontece no nível molecular e atômico, o que ainda faz pouco ou nenhum sentido neste nível da escolaridade (BRASIL, 1998, p. 98).
}

Por consequência, esses conteúdos tratados de forma não qualitativa e abrangendo detalhes em nível atômico, podem gerar dificuldades e limitações na aprendizagem de Química por parte dos alunos, como a dificuldade na abstração desses conteúdos, que possuem alta complexidade por não serem visíveis ou palpáveis e a imposição da memorização desnecessária, que podem ser uma base para os obstáculos enfrentados na aprendizagem dos anos seguintes (PITOMBO E MARCONDES, 1992).

Os professores também citam, como segue, que todos os conteúdos assinalados "são importantes", pois são a "base" para o Ensino Médio, mesmo estando cientes do escasso tempo e do excesso de conteúdos:

P3: "Eu não tiraria nenhum conteúdo, porque 9o ano é a base pra ele chegar no Ensino Médio [...] Eu sei que é bastante conteúdo, mas eu vou falar pra você que eu dou tudo isso aí."

Concordamos assim com o que se refere ao suporte e a importância que é conferida ao nono ano do Ensino Fundamental para o entendimento da Química, considerando que, pode ser o primeiro contato dos iniciados com esta ciência. A questão se dirige ao fato de conceder a quantidade de conteúdos uma boa "base" para os estudos futuros em relação à prioridade que pode ser dada a construção dos conceitos por uma perspectiva mais construtivista e significativa que demanda tempo, dedicação, profundidade e envolvimento dos sujeitos participantes do 
processo. A temática dos conteúdos e temas também é incitada pelo discurso de P4 e P1:

P4: "Porque o 9o ano é só uma pincelada, ele não se aprofunda tanto, e vê um pouquinho de tudo."

P1: "São todos importantes, é uma base né, para o 1ㅇano, porque se ele chegar lá no Ensino Médio sem essa noção, o professor não vai trabalhar todos esses detalhes."

No entanto, apesar de salientar a importância do desenvolvimento de temas, percebe-se que os professores pesquisados ainda preocupam-se com o excesso de conteúdos, atribuindo o papel prioritário do Ensino Fundamental, de apresentar uma base ao Ensino Médio, comentando os conteúdos brevemente com "pinceladas", como evidenciado nas falas de P3, P4 e P1, nos fazendo pensar sobre a necessidade de tratar todos os conteúdos de forma superficial nessa etapa escolar o que não é preconizado pelos PCNs. Assim, com relação ao seu texto, no que se refere à escolha dos conteúdos, o direcionamento dos PCNs prevê critérios bem delineados, enfatizando a importância da seleção destes conteúdos, bem como, a profundidade com a qual devem ser desenvolvidos. Dessa forma enfatizam:

Os conteúdos devem favorecer a construção, pelos estudantes, de uma visão de mundo como um todo formado por elementos interrelacionados, entre os quais o ser humano, agente de transformação. Devem promover as relações entre diferentes fenômenos naturais e objetos da tecnologia, entre si e reciprocamente, possibilitando a percepção de um mundo em transformação e sua explicação científica permanentemente reelaborada;

Os conteúdos devem ser relevantes do ponto de vista social, cultural e científico, permitindo ao estudante compreender, em seu cotidiano, as relações entre o ser humano e a natureza mediadas pela tecnologia, superando interpretações ingênuas sobre a realidade à sua volta. Os temas transversais apontam conteúdos particularmente apropriados para isso;

\footnotetext{
Os conteúdos devem se constituir em fatos, conceitos, procedimentos, atitudes e valores a serem promovidos de forma compativel com as possibilidades e necessidades de aprendizagem do estudante, de maneira que ele possa operar com tais conteúdos e avançar efetivamente nos seus conhecimentos (BRASIL, 1998, p. 35).
}

Apesar de a escola ter certa autonomia no que diz respeito à escolha dos conteúdos, tornando seu planejamento e objetivos de ensino mais adequados à realidade da comunidade escolar, o excesso de conteúdos pode ser um obstáculo para as práticas educativas, pois não depende somente dos professores, mas também dos conteúdos que são listados pela Secretaria de Educação do Estado, bem como dos livros didáticos que são aceitos pelo Programa Nacional do Livro Didático (PNLD) de 2017, que apresenta um rol bem variado e extenso de conteúdos, como as reações químicas, elementos químicos e suas ligações, os átomos, sua estrutura e balanceamento de equações. Cabe então ao professor a seleção adequada e o estudo sobre as melhores perspectivas de ensino, de forma a contemplar objetivos mais adequados para sua aprendizagem, tomando o lugar das simples "noções" como requisitos da aprendizagem. 


\section{INSTRUMENTOS AVALIATIVOS}

No que diz respeito à categoria avaliação apresentada no Quadro 1, foi possível perceber, quando questionou-se os professores sobre quais instrumentos eles utilizavam para avaliar a aprendizagem dos seus alunos, que para os docentes a avaliação tinha grande importância e que utilizam-se diversos instrumentos avaliativos, como destacamos nas falas obtidas por meio das entrevistas:

P4: "Exercícios para memorizar e depois prova, trabalhos, relatório de aulas práticas[...]"

P1: "Eu avalio com prova, quando ia pro laboratório eu pedia relatório, anotações das observações, trabalho, pesquisa em casa, ou nos livros em sala, tarefa, a feira de ciências[...]"

P5: "Trabalho, lista de exercícios, principalmente quando envolvia cálculo, quando trabalho com aula prática peço introdução de relatório, para aprenderem a fazer relatório e a prova[...]"

Logo, pelos relatos é perceptível o uso de diversas ferramentas utilizadas pelos professores em suas práticas educativas, como relatórios de aulas experimentais, listas de exercícios, a escrita sobre as observações e de construções conceituais, pesquisas em livros ou outros meios de informações, participação em feiras de ciências, conforme é ressaltada a importância dessa prática pelos PCNs: "Dessa forma, é fundamental que se utilizem diversos instrumentos e situações para poder avaliar diferentes aprendizagens" (BRASIL, 1998, p. 31).

Apesar dos professores perceberem a importância do uso de diversos instrumentos avaliativos, como se preconiza nos PCNs, a concepção de avaliação formativa ainda é precária, pois utiliza-se mais a avaliação classificatória e memorística, por meio das notas, perceptível na fala dos professores, que citam como instrumentos avaliativos, exercícios para memorização, introduções de relatórios sobre experimentos, tarefas, e sempre valorizando a prova como o instrumento mais importante. A utilização desses recursos não favorece a perspectiva formativa de avaliação, mas sim a avaliação para a classificação, denotando uma visão ainda tradicional e limitada em suas práticas educativas de como avaliar.

Assim sendo, a avaliação é um ato pedagógico que deve promover reflexões e mudanças nas práticas educativas, pois por meio dela é possível compreender e identificar o que os estudantes aprenderam, seus avanços e também dificuldades, já que esses aspectos estão diretamente relacionados às práticas do professor, dentro e fora de sala de aula.

\section{DIFICULDADES NA FORMAÇÃO}

A categoria dificuldades na formação emergiu quando os professores foram indagados sobre as adversidades enfrentadas devido a sua formação inicial, sendo perceptível que alguns deles concordam que existam problemas tanto nos saberes pedagógicos quanto específicos, provindos da formação inicial, tanto em Ciências Biológicas quanto em Ciências plena: 
P1: “Nós não temos todo esse conhecimento de quem faz só a Química, acho que deixa a desejar nas licenciaturas".

P4: “O 9o ano eu acho difícil, exatamente por a gente não ter essa preparação da Química e da Física".

Assim, a formação inicial problemática que acomete tanto a formação específica quanto a pedagógica, pode interferir nas práticas dos professores de Ciências, pois segundo Milaré e Pinho Alves (2010), sem uma formação adequada, os professores não possuem meios para renovar e incluir a contextualização de conteúdos químicos em suas aulas, já que não possuem o saber pedagógico particular da disciplina de Química, além de se sentirem inseguros em relação ao conteúdo, mesmo que para esta etapa de escolaridade não deva ser específico. No entanto, é importante que os professores tenham a percepção sobre essas dificuldades e reflitam sobre suas práticas educativas, entendendo que existem problemas para assim serem superados, como relatado pelos professores P1 e P4, que veem a importância da formação continuada e da reflexão.

Mesmo no contexto da educação, a não inquietação, a estagnação com relação às práticas educativas pode ser também um problema que deve ser ultrapassado, pois alguns professores, como P3, não veem impasses em suas práticas, dificultando o processo de reflexão sobre as suas dificuldades, pois se restringem ao saber científico no que se refere a uma boa aula de Ciências:

P3: “Não tenho dificuldade, eu gosto[...] ]eu prefiro o 9 ano, porque eu adoro Química e Física, por mais que eu sou formada em ciências biológicas".

Consideramos assim, a importância do reconhecimento sobre as limitações da prática educativa, como na percepção do professor P1 quando indica a importância dos cursos de formação, que garantem formação continuada de qualidade e estudos, como também P4, que está ciente da necessidade permanente de aprender a ensinar:

P1: "O que foi importante pra mim foi os cursos que a gente fazia na universidade, de formação continuada anual".

P4: "A gente aprende muito mais estudando pra dar aula[...]".

Zabala (1998) compreende que, a ausência da percepção sobre os problemas existentes e a falta de reflexões sobre a prática pedagógica, refletem sobre as ações docentes, sendo um obstáculo na melhoria de suas próprias práticas educativas e na formação continuada:

\begin{abstract}
A intervenção pedagógica tem um antes e um depois que constituem as peças substanciais em toda prática educacional. O planejamento e a avaliação dos processos educacionais são uma parte inseparável da atuação docente, já que o que acontece nas aulas, a própria intervenção pedagógica, nunca pode ser entendida sem uma análise que leve em conta as intenções, as previsões, as expectativas e a avaliação dos resultados (ZABALA, 1998, p. 17).
\end{abstract}

Por certo, a prática educativa não pode ser reduzida somente ao instante em sala, mas ampliando à reflexão ao antes, durante e depois, que compõem as etapas do processo da prática pedagógica do professor, para que haja melhorias.

Portanto, as dificuldades enfrentadas pelos professores existem e interferem 
somente na formação inicial e continuada, como comenta Hagemeyer (2004), sobre as adversidades relacionadas às imposições curriculares, trabalho intensificado, as responsabilidades e desvalorização da função, o contexto de excesso de alunos, salários precários, falta de materiais, entre outras, que geram obstáculos na função de ser professor. Assim se faz necessário, como afirma Dourado (2007), rever a formação inicial pedagógica, de forma a se articular as políticas educacionais, as concepções de formação inicial e continuada, sistemas de ensino, estrutura curricular, gestão e organização, que são obstáculos na prática do professor.

\section{CONSIDERAÇÕES FINAIS}

Ao final, percebeu-se com a pesquisa que somente a análise do discurso pode não ser suficiente para conhecer a fundo a prática dos professores entrevistados, sendo necessária assim, uma observação dessa prática, pois nem sempre a fala condiz com a ação. Mesmo assim, foi possível conhecer um pouco sobre essas práticas, discutindo-as e argumentando-as por meio dos pressupostos teóricos empregados, que foram satisfatórios para a análise e compreensão dos dados, entendendo um pouco mais como as práticas educativas contribuem no processo de ensino e de aprendizagem.

Ainda, em termos de considerações, compreendemos que as práticas dos professores de ensino de Ciências ainda enfatizam a concepção da experimentação como uma comprovação da teoria, o que pode não garantir a compreensão dos conhecimentos científicos e de como se faz ciências, aspectos considerados importantes para que se tenha uma formação mais ampla, objetivo este determinado para o final do Ensino Fundamental em Ciências. Entendemos também, que os professores procuram promover a aprendizagem dos conteúdos por meio de alguns temas, instrumento este que possibilita uma visão mais crítica e abrangente, tanto do professor, quanto dos alunos, no entanto, também se preocupam com o excesso de conteúdos, já que estes fazem parte da tradição escolar e são posicionados, por exemplo, pelas Diretrizes Curriculares do Estado do Paraná.

No que diz respeito à avaliação, a concepção dos professores entrevistados ainda recai sobre os métodos e a quantidade de atividades que são aplicadas aos alunos. Mais que o número, se deve dar espaço para que a avaliação seja percebida como um ato de reflexão da prática pedagógica e de auto avaliação dos alunos, pois dessa forma, a avaliação supera o objetivo de apenas classificar, que para o Ensino Fundamental, pode trazer prejuízos quanto à formação para educação científica, que nega, por exemplo, o ensino por memorização. Claro que não se deve pensar nesse processo como algo simples, pois tange outros aspectos, como as concepções de educação da escola, o currículo extenso e a formação reflexiva, no entanto, devemos ampliar o conceito da prática da avaliação de modo que se renove e se integre também outros pontos que se referem às práticas educativas. 


\title{
Speeches of Science teachers about their educations techniques: The Chemistry classes in the final years of Middle School
}

\begin{abstract}
The natural science teaching in the final year of Middle School has become mandatory by the law $n^{\circ} 5.692 / 71$, and, also, specifically, in the ninth grade, subjects as Chemistry and Physics are studied, as oriented by National Curricular Parameters - NCPs. Therefore, the pedagogical practice used by the teachers are very important in order to prevent the science teaching to be an obstacle to the students, reaching the objectives of helping to comprehend the world and act as individual and as a citizen, using the knowledge of scientific and technological nature. Hence, this current research had the objective to investigate the science teachers' practices in the final years of Middle School. The data of this study, which were obtained by semi-structured interviews, made with five public school system teachers from three schools of the cities of Maringa and Atalaia, show that the teachers have difficulties in developing educative practices that reach the CNPs, related to Chemistry, such as, the contents contextualization and its development, through themes, besides experimentation.
\end{abstract}

KEYWORDS: Science Teaching. Teacher Education. Teaching Practice. 


\section{AGRADECIMENTOS}

Aos professores que participaram da entrevista, disponibilizando seu tempo e conhecimentos, que são relevantes para futuras discussões sobre as práticas educativas.

\section{REFERÊNCIAS}

ARROIO, A. O show da Química: motivando o interesse científico. Química Nova na Escola, v. 29, n. 1, 2006. Disponível em:

$<$ http://quimicanova.sbq.org.br/imagebank/pdf/Vol29No1 $173 \quad 30-$ ED04399.pdf> Acesso em: 12 de Abr. 2017.

BRASIL. Parâmetros Curriculares Nacionais (PCNs). Ciências Naturais. Ensino Fundamental. Terceiro e quarto ciclos. Brasília: MEC/SEF, 1998.

BRASIL. Secretaria de Educação Fundamental. Parâmetros curriculares nacionais: Ciências Naturais / Secretaria de Educação Fundamental. Brasília : MEC / SEF, 1998.

CABRERO, B. G.; LOREDO E. J.; CARRANZA P. G. Análisis de la práctica educativa de los docentes: pensamiento, interacción y reflexión. REDIE, Ensenada, v. 10, n. spe, p. 1-15, enero 2008. Disponível em:

<http://www.scielo.org.mx/scielo.php?script=sci_arttext\&pid=S160740412008000300006\&lng=es\&nrm=iso>. Acesso em:25 abr. 2017.

CACHAPUZ, A.; GIL-PEREZ, D.; CARVALHO, A. M.; PRAIA, J.; VILCHES. (Org.) A necessária renovação do ensino de ciências. São Paulo: Cortez, 2005.

COSTA, J. de M.; PINHEIRO, N. A. M.O ensino por meio de Temas-Geradores: A educação pensada de forma contextualizada, problematizada e interdisciplinar. Imagens da Educação, v. 3, n. 2, p. 37-44, 2013.

CUNHA, M. da F.; CAMPOS, L. L. M. O discurso e a prática pedagógica de professores de ciências no ensino fundamental. In: PIROLA, Nelson Antonio (Org.) Ensino de ciências e matemática IV: temas de investigação. São Paulo: Unesp, 2010.

DELIZOICOV, D.; ANGOTTI, J. A.; PERNAMBUCO, M. M. Ensino de ciências: fundamentos e métodos. 3ed. São Paulo: Cortez, 2002. 
Outubro, 2007. Disponível em <http://www.cedes.unicamp.br> Acesso em: 28 de Abr. 2017.

FURMAN, M. $O$ ensino de ciências no ensino fundamental: colocando as pedras fundacionais do pensamento científico. São Paulo: Instituto Sangari, 2009.

GIMENO SACRISTÁN, J. Poderes instáveis em educação. Porto Alegre: ARTMED Sul, 1999.

GIORDAN, M. O papel da experimentação no ensino de ciências. Química Nova na Escola. N. 10, Novembro, 1999. Disponível em:

$<$ http://anesc.sbq.org.br/online/qnesc10/pesquisa.pdf> Acesso em: 26 de abr. 2017.

GONÇALVES, P. F; MARQUES, C. A. Contribuições pedagógicas e epistemológicas em textos de experimentação no ensino de Química. Investigações em Ensino de Ciências, v. 11, n. 2, p. 219-238, 2006. Disponível em:

<https://www.if.ufrgs.br/cref/ojs/index.php/ienci/article/view/494/297> Acesso em: 26 de Abr. 2017.

HAGEMEYER, R. C. de C.; Dilemas e desafios da função docente na sociedade atual: Os sentidos da Mudança; Rev. Educar, Curitiba, n. 24, p. 67-85, 2004. Editora UFPR. Disponível em: <http://www.scielo.br/pdf/er/n24/n24a04.pdf> Acesso em: 10 de Fev. 2017.

MILARÉ, T.; PINHO ALVES, J. A Química disciplinar em ciências do 9o Ano. Química Nova na Escola, v. 32, n. 1, FEVEREIRO 2010. Disponível em $<$ http://webeduc.mec.gov.br/portaldoprofessor/quimica/sbq/QNEsc32 1/09-PE0909.pdf > Acesso em: 10 de Fev. 2017.

MILARÉ, T.; PINHO ALVES, J. A Química no nono ano do Ensino Fundamental: da disciplinaridade à alfabetização científica e tecnológica. Rev. Ensaio, Belo Horizonte, v. 12, n. 2, 2010. Disponível em <http://www.scielo.br/pdf/epec/v12n2/1983-2117-epec-12-02-00101.pdf> Acesso em: 21 de Fev. 2017.

MINAYO, M. C. de S.(Org); DESLANDES, S. F.; GOMES, R. Pesquisa social: teoria, método e criatividade.28. ed. Petrópolis: Vozes, 2009.

MORAIS, R.; GALIAZZI, M.C. Análise Textual Discursiva. 2. Ed. rev. Rio Grande do Sul: Ed. Unijui, 2011. 
NASCIMENTO, F.; FERNANDES, H. L.; MENDONÇA, V. M. O ensino de ciências no Brasil: história, formação de professores e desafios atuais. Revista HISTEDBR Online, Campinas, n. 39, p. 225-249, 2010.

PITOMBO, R. M. L.; MARCONDES, R. M. E. Ideias sobre a transmissão do conhecimento Químico. GEPEQ/ Instituto de Química da USP, 1992.

SASSERON, H. L.; CARVALHO, A. M. Almejando a alfabetização científica no Ensino Fundamental: A proposição e a procura de indicadores do processo. Investigações em Ensino de Ciências, v. 13, n.3, p. 333-352, 2008.

SILVA, J. L. P. B.; MORADILLO, E. F. De. Avaliação, ensino e aprendizagem de ciências. Rev.Ensaio, Belo Horizonte, v. 4, n. 1, Junho 2012. Disponível em: <http://www.scielo.br/pdf/epec/v4n1/1983-2117-epec-4-01-00028.pdf> Acesso em: 28 de Abr. 2017.

ZABALA, A. A prática educativa: como ensinar. Porto Alegre: Artmed, 1998.

ZANON, D. A. V.; FREITAS, D. A aula de ciências nas séries iniciais do ensino fundamental: ações que favorecem a sua aprendizagem. Ciências \& Cognição, v. 10, 2007.

Recebido: 29 mai. 2017

Aprovado: 06 set. 2017

DOI: $10.3895 /$ actio.v2n2.6819

Como citar:

SEMENSATE, A. P.; CEDRAN, D. P. Discursos de professores de Ciências sobre suas práticas educativas: as aulas de Química nos anos finais do Ensino Fundamental. ACTIO, Curitiba, v. 2, n. 2, p. 43-60, jul./set.

2017. Disponível em: <https://periodicos.utfpr.edu.br/actio>. Acesso em: XXX

Correspondência:

Amanda Pini Semensate

Rua Paraná, n² 200, Atalaia, Paraná, Brasil. CEP: 87630000

Direito autoral: Este artigo está licenciado sob os termos da Licença Creative Commons-Atribuição 4.0

Internacional.

(c) (i) 